NASA/TM-2003-212708
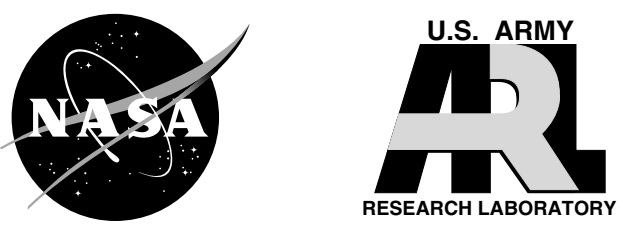

\title{
Cooperative Multi-Agent Mobile Sensor Platforms for Jet Engine Inspection- Concept and Implementation
}

Jonathan S. Litt

U.S. Army Research Laboratory, Glenn Research Center, Cleveland, Ohio

Edmond Wong, Michael J. Krasowski, and Lawrence C. Greer

Glenn Research Center, Cleveland, Ohio 
Since its founding, NASA has been dedicated to the advancement of aeronautics and space science. The NASA Scientific and Technical Information (STI) Program Office plays a key part in helping NASA maintain this important role.

The NASA STI Program Office is operated by Langley Research Center, the Lead Center for NASA's scientific and technical information. The NASA STI Program Office provides access to the NASA STI Database, the largest collection of aeronautical and space science STI in the world. The Program Office is also NASA's institutional mechanism for disseminating the results of its research and development activities. These results are published by NASA in the NASA STI Report Series, which includes the following report types:

- $\quad$ TECHNICAL PUBLICATION. Reports of completed research or a major significant phase of research that present the results of NASA programs and include extensive data or theoretical analysis. Includes compilations of significant scientific and technical data and information deemed to be of continuing reference value. NASA's counterpart of peerreviewed formal professional papers but has less stringent limitations on manuscript length and extent of graphic presentations.

- TECHNICAL MEMORANDUM. Scientific and technical findings that are preliminary or of specialized interest, e.g., quick release reports, working papers, and bibliographies that contain minimal annotation. Does not contain extensive analysis.

- CONTRACTOR REPORT. Scientific and technical findings by NASA-sponsored contractors and grantees.
- CONFERENCE PUBLICATION. Collected papers from scientific and technical conferences, symposia, seminars, or other meetings sponsored or cosponsored by NASA.

- SPECIAL PUBLICATION. Scientific, technical, or historical information from NASA programs, projects, and missions, often concerned with subjects having substantial public interest.

- TECHNICAL TRANSLATION. Englishlanguage translations of foreign scientific and technical material pertinent to NASA's mission.

Specialized services that complement the STI Program Office's diverse offerings include creating custom thesauri, building customized databases, organizing and publishing research results ... even providing videos.

For more information about the NASA STI Program Office, see the following:

- Access the NASA STI Program Home Page at http://www.sti.nasa.gov

- E-mail your question via the Internet to help@sti.nasa.gov

- Fax your question to the NASA Access Help Desk at 301-621-0134

- Telephone the NASA Access Help Desk at 301-621-0390

- Write to:

NASA Access Help Desk

NASA Center for AeroSpace Information 7121 Standard Drive

Hanover, MD 21076 
NASA/TM-2003-212708

ARL-TR-3054
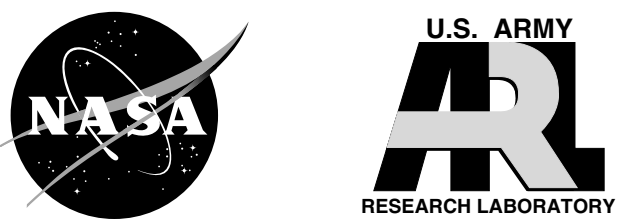

\section{Cooperative Multi-Agent Mobile Sensor Platforms for Jet Engine Inspection- Concept and Implementation}

Jonathan S. Litt

U.S. Army Research Laboratory, Glenn Research Center, Cleveland, Ohio

Edmond Wong, Michael J. Krasowski, and Lawrence C. Greer

Glenn Research Center, Cleveland, Ohio

Prepared for the

International Conference on Integration of Knowledge Intensive Multi-Agent Systems sponsored by the Institute of Electrical and Electronics Engineers

Cambridge, Massachusetts, October 1-3, 2003

National Aeronautics and

Space Administration

Glenn Research Center 
This work was sponsored by the Low Emissions Alternative Power Project of the Vehicle Systems Program at the NASA Glenn Research Center.

Available from

NASA Center for Aerospace Information 7121 Standard Drive

Hanover, MD 21076
National Technical Information Service 5285 Port Royal Road Springfield, VA 22100

Available electronically at http:/ /gltrs.grc.nasa.gov 


\title{
Cooperative Multi-Agent Mobile Sensor Platforms for Jet Engine Inspection-Concept and Implementation
}

\author{
Jonathan S. Litt \\ U.S. Army Research Laboratory \\ National Aeronautics and Space Administration \\ Glenn Research Center \\ Cleveland, Ohio 44135
Edmond Wong, Michael J. Krasowski, and Lawrence C. Greer
National Aeronautics and Space Administration
Glenn Research Center
Cleveland, Ohio 44135

\begin{abstract}
Cooperative behavior algorithms utilizing swarm intelligence are being developed for mobile sensor platforms to inspect jet engines on-wing. Experiments are planned in which several relatively simple autonomous platforms will work together in a coordinated fashion to carry out complex maintenance-type tasks within the constrained working environment modeled on the interior of a turbofan engine. The algorithms will emphasize distribution of the tasks among multiple units; they will be scalable and flexible so that units may be added in the future; and will be designed to operate on an individual unit level to produce the desired global effect. This proof of concept demonstration will validate the algorithms and provide justification for further miniaturization and specialization of the hardware toward the true application of on-wing in situ turbine engine maintenance.
\end{abstract}

\section{INTRODUCTION}

Modern jet engines undergo regular maintenance inspections for the purpose of detecting evidence of internal distress such as cracking or erosion. The inspection methods range from the minimally invasive borescopic to those requiring full teardown. Borescopic inspections, which consist of an interior visual inspection using a flexible tool inserted through a view port, are performed on-wing, resulting in little downtime. Full teardowns, on the other hand, result in much lost on-wing time and significant cost to the operator, but they do allow for more thorough inspections simply because the maintainer has better access to the internal components, and teardowns are often required for repair or replacement of worn or damaged parts.
It is highly desirable to reduce the requirement for teardowns, but at the same time it is unacceptable to compromise safety. If much of the inspection and repair that currently requires teardown could be performed onwing, it would be a boon to the airline industry, from the point of view of both early detection of potential problems and lower maintenance costs.

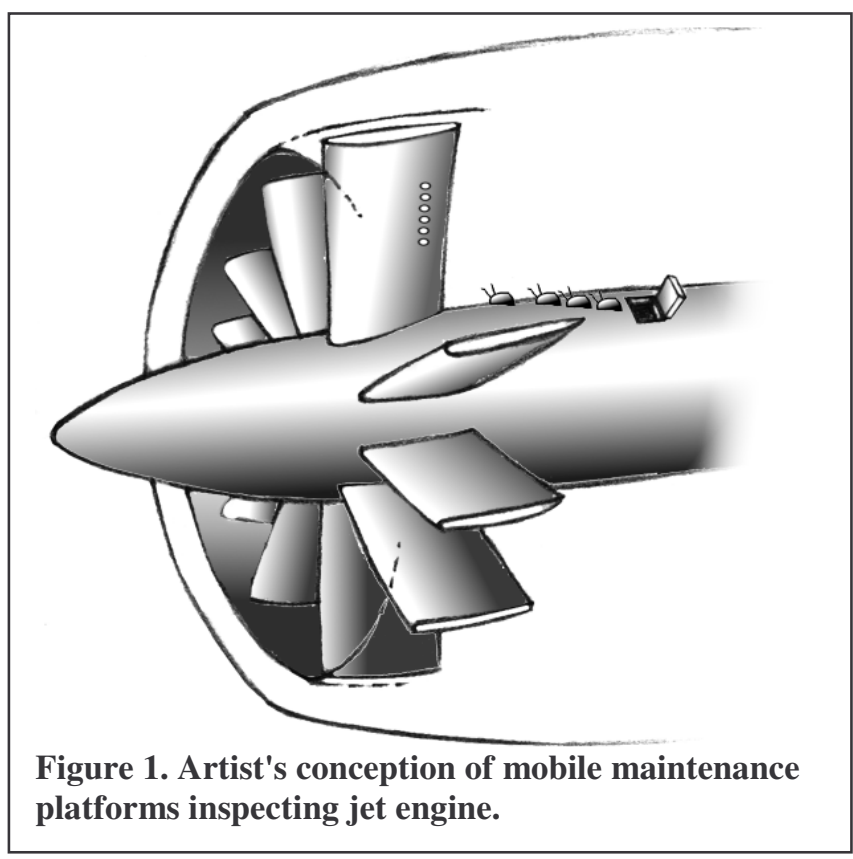

Miniature mobile sensor platforms that can roam the surfaces inside of an engine while it is shut down may be able to perform such a maintenance function. Through their ability to move about freely and autonomously in confined spaces and perceive and communicate information, they can thoroughly search all exposed surface areas for damage or wear. Subsequently, they can redirect themselves to problem areas, potentially providing a repair. Combining many such miniature mobile sensor platforms into a collaborative multi-agent system may enable the inspection and repair of jet engines, thus replacing some of the human intervention currently required in the maintenance cycle. (Figure 1). 


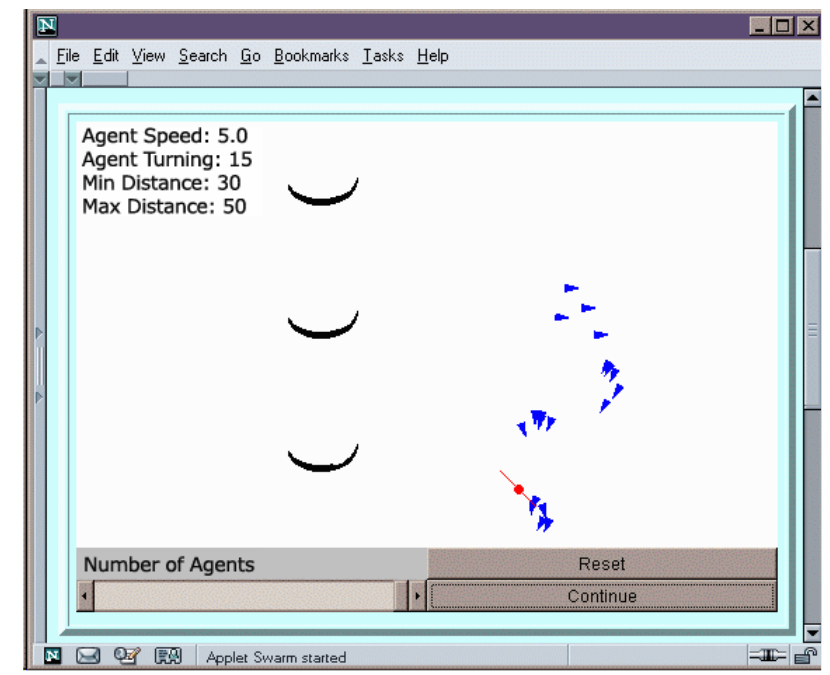

Figure 2. Preliminary simulation of agents flocking to a crack in a jet engine.

Work is ongoing at NASA Glenn Research Center and university partner California Institute of Technology to develop the underlying technology to enable the realization of such a system. It is envisioned that a collaborative swarm of these mobile agents will rove through an engine in a highly coordinated fashion, thoroughly searching engine surfaces to assess damage. Once damage is detected, the location and damage type information will be disseminated, possibly alerting the appropriate group of agents to converge and perform the necessary repairs.

Due to the tiny size of these agents, it is likely that they will only contain simple on-board intelligence. As a result, each individual will only be imbued with the ability to follow simple behavioral controls. However, it is envisioned that the combined interaction of the individual units will result in the emergence of a complex group behavior that assures a thorough and methodical search for damage.

The current work entails developing the technology to implement a small scale arena demonstration that tests the feasibility of a cooperative multi-agent inspection system. After providing some application background, this paper will discuss the two primary technology areas being developed in parallel: the hardware implementation of prototype mobile sensor platforms and the application of collaborative control algorithms. The hardware discussion will describe the development and evolution of the prototype mobile sensor platforms. The controls discussion will describe the application of Swarm Intelligence based algorithms to enable a group of mobile sensor platforms to accomplish coordinated movement, efficient searches and collaborative goal achievement within the demonstration environment. In addition, the demonstration tests that will be used to validate the swarm algorithms will be described (Figure 2).

\section{APPLiCATION BACKGROUND}

The types of engine inspection that can be performed either visually or with specific sensors could be performed in situ, given the technology to deliver the test devices to the appropriate location within the engine. Mobile sensor platforms designed to move within the confines of the engine provide hope that someday full engine inspections will be able to be performed on-wing. The outcome of this program will be a proof of concept demonstration.

\subsection{NONDESTRUCTIVE TESTING METHODS}

Commonly used nondestructive engine component testing methods [1] include: Visual/Borescopic; Eddy Current; Ultrasonic; liquid penetrant; and magnetic particle. Some other, less commonly used techniques include radiography; acoustic emission; thermography; holography; shearography; and tap testing. Of all of these techniques, only the visual inspection is currently performed on-wing except in very specialized cases, the rest are bench tests. There has been a preliminary effort to try to transition some other techniques to on-wing [2] for improved safety, but the problems remain concerning the way to get the test equipment into the confined space to perform the inspection.

Postage stamp size integrated sensor (or "lick and stick") technology that may be attached directly to components to provide constant self-awareness of the engine's health [3] is an alternative to the current system of after-the-fact inspection. Generally manufacturers are unwilling to add sensors to engines without very good reason because they are perceived as adding cost and complexity while reducing reliability. The mobile sensor platforms offer a link between the current system and the integrated sensor approach because they provide some of the same component health monitoring capabilities while overcoming many of the issues that create the reluctance to add sensors. They are temporary and removable so sensor failures do not result in down time of the engine, they are reusable so a different set is not needed for each engine, and they do not require the engine to be modified.

With the motivation to move as much testing as possible to the wing-mounted engine, mobile sensor platforms provide a way to deliver the sensors and perform tests like those currently performed in the shop. Thus some of the current bench test techniques can be directly duplicated by the mobile sensor platforms, while others might be replaced by an equivalent test using new technology.

\subsection{REPAIR METHODS}

Some of the standard engine component repair methods include: boring, grinding, blending, welding, plating, 
painting, coating, straightening, etc. [4]. The problems and logistics associated with making these repairs in situ are far greater than those that arise with the inspections (dust and residue generation, extreme heat, etc.), but it is still quite conceivable that some of the less harsh techniques might someday be developed to such a level that they are safe to perform within the engine.

\section{Mobile Sensor Platform Description}

The mobile sensor platforms used here have developed from a general archetype, whose descendants have evolved and shrunk with each generation, but all contain the same characteristics of on-board power, communication capability, video output, and a sensor payload bay [5]. The original intention was to create a platform which could be sent into non-human safe/accessible areas and to transmit back video, sound and other sensed variables. As the incarnations progressed, the platforms shrunk yet gained communications capabilities. For example, the original platform received command and control and returned video. The latest platform can also return sensor data along with video and can network with other platforms. This being the case, the present effort has the volume in its sensor bay for a video camera and in its battery bay, a cell sufficient to power the camera and the motor drives. This configuration is considered to be the upper end of the sensor power and volume budget. Thus, any other sensor ensemble, for example microphones, electronic noses, pressure transducers, etc. can be expected to fall within the power budget of the platform and volume of the camera bay and so would require minimal if any modification. These units have been designed as general purpose vehicles, for such possible uses as planetary exploration and astronaut-to-equipment communication. They have not been optimized for the engine inspection application in terms of size-limiting components and as such are useful through the proof of concept phase but not beyond. Less reliance on commercial, off-the-shelf hardware and more custom design and machining of parts would allow for a more appropriate product for the application, but at the cost of significant time and money, which is only justified by the decision to move on to a real implementation.

As previously stated, the mobile sensor platforms carry their own power, but sometimes the application dictates that more power is required than a battery can supply, forcing the use of an external power source and a tether [6]. This situation might be exacerbated by the requirement for stronger motors to drag the trailing cable. The question of whether or not the mobile platforms should be tethered arises for two distinct reasons. Miniaturization is a requirement for movement within an engine. Blade spacing might be half an inch or less with the added complication of a camber (turn) to maneuver through. Clearances at the blade tips on the order of mils make an overhead examination impossible. Thus the length of the platform is limited if it is required to move between stages of the compressor or turbine (Figure 3). With current technology and the in-house design requirements, the platforms' size is constrained by the size of the power supply or battery, which presently is an ICR2 photo cell (Figure 4). Thus, at least for the near future, an external power supply with a cable connection is required if the platform is to reach the necessary size (Figure 5).
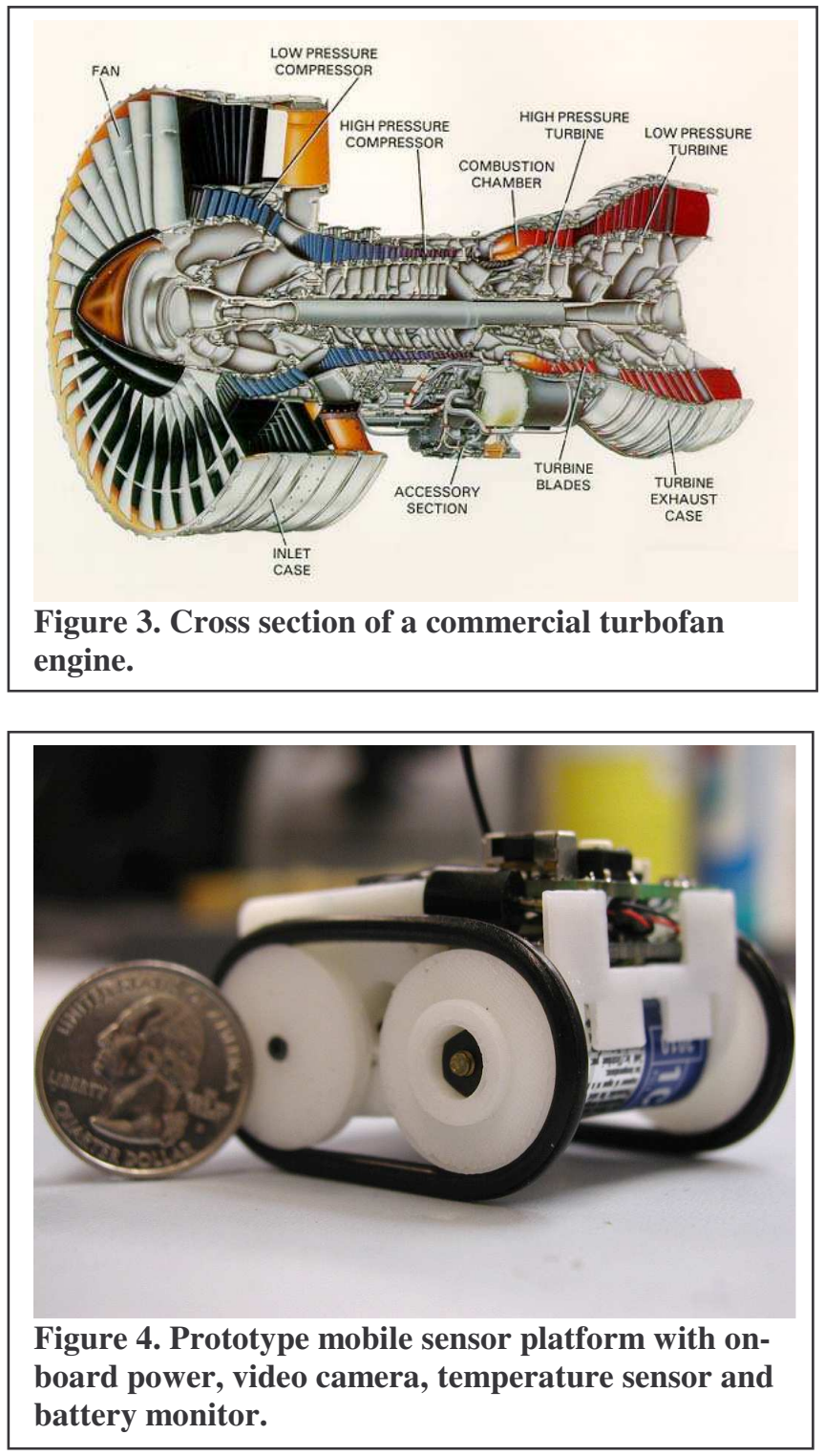

The other requirement for tethering is potentially a regulatory one. Allowing foreign objects inside an engine poses a risk of damage. Parts and equipment inadvertently left in or near an engine have caused foreign object damage (FOD) [7,8]. Abandoned roving robots within turbomachinery could also generate FOD as they are sucked through the engine at startup, and might even cause it to seize. Foreign object damage caused by a single loose platform and the subsequent engine dismantling and repair could more than eradicate the savings generated by the mobile sensor platforms. Tethering would provide an indication that there are still platforms inside the engine as 

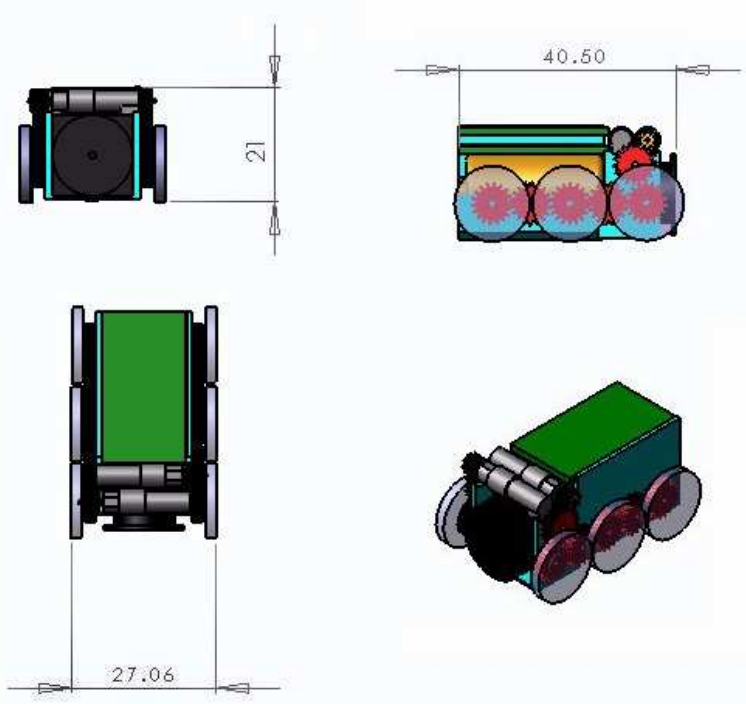

Figure 5. Smallest NASA Glenn in-house design, as yet unbuilt, dimensions are in millimeters.

well as how many, and would possibly provide a means to pull disabled platforms out, which could be accomplished using fishing line for the tether even with on-board power. It is likely that, for this application, adding a tether would mean adding an on-board reel to wind up the slack on exit as well.

\section{SWARM ALGORITHMS}

Swarm algorithms provide scalability of the control architecture, flexibility as units can be dynamically added or removed without explicit reorganization, and robustness through redundancy and simplicity of the units [9]. Thus they lend themselves very well to the jet engine inspection application because they support the validity of the small scale test bed demonstration with several similar mobile sensor platforms. The specific issues associated with the application-the constrained environment with little maneuvering room and less passing room, yet the required collaboration in inspection and possibly repair-make formation control [10] essential to the success of the task, which relies on getting the right capabilities to a certain location within the engine [11]. Some initial experiments will focus on issues that are functions of the test bed and ultimately the environment within an engine: the types of communication required to perform the collaborative tasks [12], and the types and locations of sensors required for such communication [13] (this is separate from the question of which sensors are required for the actual component inspection, which is not part of this portion of the research). Additionally, as the tasks become defined in terms of what the true inspection procedure and possible repair will entail, the experiments will be designed to investigate such problems as exploration strategies guaranteeing completeness of coverage [14], division of labor and allocation of workers [15], group size [16], and specialization of agents [17], which is expected to be particularly important as in situ component testing methods are developed.

The issue of tethering becomes very important in the second group of experiments. Tethers add a great deal of structure to the problem because they create constraints that limit the freedom of movement of the agents and require additional path planning [18]. This structure works against the spirit of the swarm intelligence, but provides an opportunity to develop the path planning aspect of the technology.

Another key issue is the need for an efficient representation of the engine surface. Since the agents will have limited memory capacity, it might be unrealistic for each to carry with itself a map of the complex geometry of the engine. Additionally, since the swarm algorithms require each agent to have only local awareness, requiring knowledge of the entire engine layout puts an unreasonable burden on the agents. However, the exit strategy, especially in the tethered case, will demand at least memory of the complete route taken to that point.

\section{Planned Test Bed Demonstration}

The goal of the project is to have several mobile platforms move around a 2-dimensional area that represents the inside of an engine (Figure 6). Issues related to how the mobile sensor platforms will move around the cylindrical surface of a real engine without falling off will not be addressed at this stage. Mobile sensor technology will not be addressed here either, even though that is the ultimate goal of the program. The purpose of the demonstration will be to evaluate the search and convergence algorithms as well as the communications protocol within the obstacle-filled arena. The test bed will be a scale model based on the ability to miniaturize the platforms, but by no means small enough to demonstrate truly engine-insertable rovers.

The test will consist of several phases: entry, search, and coverage; damage mapping, locating, and convergence; and exit. In all cases, the on-board constrained behavior logic will be simple, but the swarm as a whole will exhibit complex, dynamic behavior. The entry, search, and coverage phase will test how the mobile platforms enter the arena, how they distribute themselves, and how thoroughly they check the parts they are supposed to check, i.e., are some parts missed. The damage mapping, locating, and convergence phase will test the ability of the platforms to broadcast information that allows the visualization of the surface of the engine such that the position of any platform or damage location can be interpreted and the appropriate platforms can move to the correct spot for further inspection or maintenance. Finally, the exit phase will test the ability of the rovers to move out of the engine efficiently. How the 
algorithms are developed and tested will depend significantly upon whether or not the platforms are tethered. Tethering adds multiple constraints to the problem: it limits the distance the platforms can move, it requires them to retrace their path to exit, and it requires each platform to be aware of the other platforms' tethers to avoid tangling. The thickness of the tether might add another constraint if the platforms must cross tethers in an area with limited headroom (Figure 7). This will force the rovers to plan their initial paths such that other platforms have the ability to cross their tethers if necessary. This will become critical in the convergence phase if the destination point is in a more constrained area such as the front of the turbine where damage is most likely to occur.

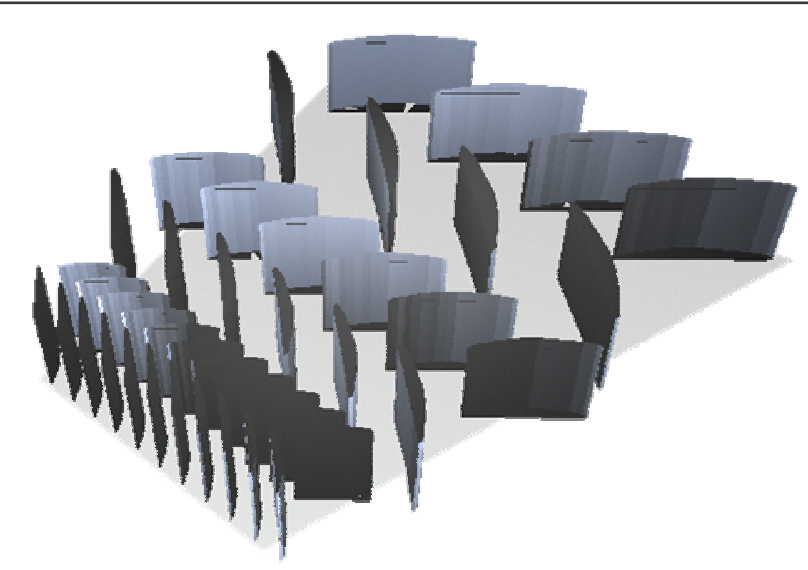

Figure 6. Possible arena test bed consisting of an "unrolled" compressor.

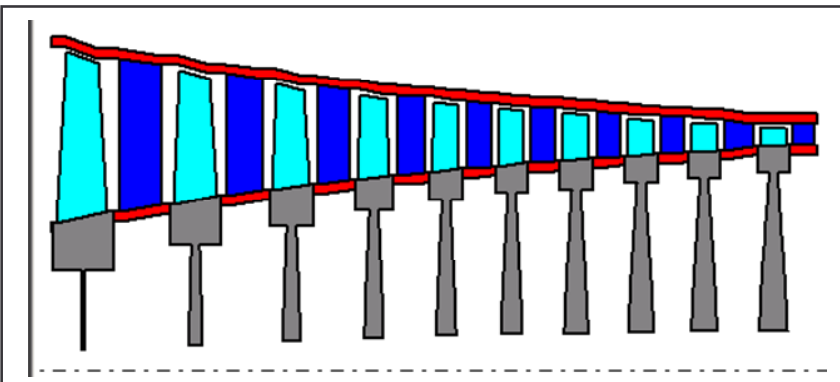

Figure 7. Compressor cross section showing increasing headroom from front (left) to back (right).

\section{SUMMARY}

There are many practical considerations that go into the development of a roving maintenance system for jet engines, and many obstacles that still need to be overcome, but the payoff is huge, both in cost and safety. This project will determine the feasibility of delivering inspection and maintenance technology, through the development of path planning and coordinated group behavior algorithms, to the necessary locations within the engine and thereby potentially delay or eliminate some costly teardowns and rebuilds. Advanced mobile sensor technology and associated processing, and possible in situ maintenance technique development are not part of this project but are being carried on in parallel. A demonstration at the end of the project will address such issues as the coverage of the search area, the communication protocol and bandwidth requirements to broadcast pertinent information, and the ability for multiple, possibly tethered vehicles to converge to a point efficiently as they move between closely spaced obstacles.

\section{REFERENCES}

1. Federal Aviation Administration, Acceptable methods, techniques, and practices-Aircraft inspection and repair, AC 43.13-1B, September 8, 1998.

2. George Y. Baaklini, Kevin Smith, David Raulerson, Andrew L. Gyekenyesi, Jerzy T. Sawacki, and Lisa Brasche, "Tools for Engine Diagnostics under the NASA Aviation Safety Program," Materials Evaluation Journal 60, 878883 , July 2002.

3. Gary W. Hunter, "Morphing, Self-Repairing Engines: A Vision for the Intelligent Engine of the Future," AIAA/ICAS International Air \& Space Symposium, AIAA 2003-3045, July 14-17, 2003.

4. Irwin E. Treager, Aircraft Engine Gas Turbine Engine Technology, $2^{\text {nd }}$ Edition, New York:McGraw-Hill, 1979.

5. Michael J. Krasowski, Lawrence C. Greer, and Lawrence G. Oberle, "Mobile Sensor Technologies Being Developed," Research \& Technology 2002, NASA/TM2003-211990, URL:

http://www.grc.nasa.gov/WWW/RT2002/5000/5520krasow ski.html].

6. Tokuji Kunorita, Shigeru Tadokoro, and Hisayuki Aoyama, "Swarm Control for Automatic Drilling Operation by Multiple Micro Robots," Proceedings of the 2001 Australian Conference on Robotics and Automation, November 14-15, 2001.

7. Joseph P. Marksteiner, "Maintenance, How Much is too Much," Joint Meeting FSF, IFA, IATA, Enhancing Safety in the $21^{\text {st }}$ Century, November 1999.

8. Brad Bachtel, "Foreign Object Debris and Damage Prevention," Aero Magazine, 1998, [on-line magazine, URL:

http://www.boeing.com/commercial/aeromagazine/aero_01/ textonly/s01txt.html].

9. Alcherio Martinoli and Kjerstin Easton, "Modeling Swarm Robotic Systems," Proc. of the Eighth International Symposium on Experimental Robotics ISER-02, July, 2002, Springer Tracts in Advanced Robotics 5 (2003), 297-306. 
10. Adam T. Hayes and Parsa Dormiani-Tabatabaei, "SelfOrganized Flocking with Agent Failure: Off-Line Optimization and Demonstration with Real Robots," Proc. of the 2002 IEEE Int. Conf. on Robotics and Automation IROS-02, May 2002.

11. William Agassounon and Alchiero Martinoli, "A Macroscopic Model of an Aggregation Experiment using Embodied Agents in Groups of Time-Varying Sizes," Proc. of the IEEE Conf. on System, Man and Cybernetics SMC02, October 2002.

12. Kjerstin Easton and Alcherio Martinoli. "Efficiency and Optimization of Explicit and Implicit Communication Schemes in Collaborative Robotics Experiments," Proc. of the IEEE Conf. on Intelligent Robots and Systems IROS-02, September-October 2002.

13. Yizhen Zhang, Alcherio Martinoli, Erik K. Antonsson, and Ross D. Olney, "Evolution of Sensory Configurations for Intelligent Vehicles," Proc. of the IEEE Intelligent Vehicles Symposium, June 2003.

14. Adam T. Hayes, Alcherio Martinoli, and Rodney M. Goodman, "Comparing Distributed Exploration Strategies with Simulated and Real Robots," Proc. of the 5th Int. Symposium on Distributed Autonomous Robotic Systems DARS-00, October, 2000.
15. William Agassounon, Alcherio Martinoli, and Rodney Goodman, "A Scalable, Distributed Algorithm for Allocating Workers in Embedded Systems," Proc. of the IEEE Conf. on System, Man and Cybernetics SMC-01, October 2001.

16. Adam T. Hayes, "How Many Robots? Group Size and Efficiency in Collective Search Tasks," Proc. of the 6th International Symposium on Distributed Autonomous Robotic Systems DARS-02, June, 2002.

17. Ling Li, Alcherio Martinoli, and Yasser S. AbuMostafa, "Emergent Specialization in Swarm Systems," Proc. of the Third International Conference on Intelligent Data Engineering and Automated Learning IDEAL-02, August 2002, Lecture Notes in Computer Science (2002), Vol. 2412, pp. 261-266.

18. F. W. Sinden, "The Tethered Robot Problem," The International Journal of Robotics Research 9, 122-133, February 1990. 
Public reporting burden for this collection of information is estimated to average 1 hour per response, including the time for reviewing instructions, searching existing data sources, gathering and maintaining the data needed, and completing and reviewing the collection of information. Send comments regarding this burden estimate or any other aspect of this collection of information, including suggestions for reducing this burden, to Washington Headquarters Services, Directorate for Information Operations and Reports, 1215 Jefferson Davis Highway, Suite 1204, Arlington, VA 22202-4302, and to the Office of Management and Budget, Paperwork Reduction Project (0704-0188), Washington, DC 20503.

\begin{tabular}{|l|l|l}
\hline 1. AGENCY USE ONLY (Leave blank) & $\begin{array}{c}\text { 2. REPORT DATE } \\
\text { November } 2003\end{array}$ & $\begin{array}{r}\text { 3. REPORT TYPE AND DATES COVERED } \\
\text { Technical Memorandum }\end{array}$ \\
\hline
\end{tabular}

4. TITLE AND SUBTITLE 5. FUNDING NUMBERS

Cooperative Multi-Agent Mobile Sensor Platforms for Jet Engine Inspection-Concept and Implementation

6. AUTHOR(S)

Jonathan S. Litt, Edmond Wong, Michael J. Krasowski, and Lawrence C. Greer

7. PERFORMING ORGANIZATION NAME(S) AND ADDRESS(ES)

8. PERFORMING ORGANIZATION REPORT NUMBER

National Aeronautics and Space Administration

John H. Glenn Research Center at Lewis Field

Cleveland, Ohio 44135-3191

WBS-22-708-87-08

1L161102AF20

E-14218

9. SPONSORING/MONITORING AGENCY NAME(S) AND ADDRESS(ES)

National Aeronautics and Space Administration

Washington, DC 20546-0001

and

U.S. Army Research Laboratory

Adelphi, Maryland 20783-1145

10. SPONSORING/MONITORING AGENCY REPORT NUMBER

NASA TM-2003-212708

ARL-TR-3054

11. SUPPLEMENTARY NOTES

Prepared for the International Conference on Integration of Knowledge Intensive Multi-Agent Systems sponsored by the Institute of Electrical and Electronics Engineers, Cambridge, Massachusetts, October 1-3, 2003. Jonathan S. Litt, U.S. Army Research Laboratory, NASA Glenn Research Center; and Edmond Wong, Michael J. Krasowski, and Lawrence C. Greer, NASA Glenn Research Center. Responsible person, Jonathan S. Litt, organization code 0300, 216-433-3748.

12a. DISTRIBUTION/AVAILABILITY STATEMENT

12b. DISTRIBUTION CODE

Unclassified - Unlimited

Subject Category: 63

Distribution: Nonstandard

Available electronically at http://gltrs.grc.nasa.gov

This publication is available from the NASA Center for AeroSpace Information, 301-621-0390.

\section{ABSTRACT (Maximum 200 words)}

Cooperative behavior algorithms utilizing swarm intelligence are being developed for mobile sensor platforms to inspect jet engines on-wing. Experiments are planned in which several relatively simple autonomous platforms will work together in a coordinated fashion to carry out complex maintenance-type tasks within the constrained working environment modeled on the interior of a turbofan engine. The algorithms will emphasize distribution of the tasks among multiple units; they will be scalable and flexible so that units may be added in the future; and will be designed to operate on an individual unit level to produce the desired global effect. This proof of concept demonstration will validate the algorithms and provide justification for further miniaturization and specialization of the hardware toward the true application of on-wing in situ turbine engine maintenance.

\section{SUBJECT TERMS}

Multi-agent system; Jet engine; Algorithms; Sensors; Autonomy; Maintenance 15. NUMBER OF PAGES 12

\begin{tabular}{|c|c|c|}
\hline $\begin{array}{c}\text { 17. SECURITY CLASSIFICATION } \\
\text { OF REPORT } \\
\text { Unclassified }\end{array}$ & $\begin{array}{c}\text { 18. SECURITY CLASSIFICATION } \\
\text { OF THIS PAGE } \\
\text { Unclassified }\end{array}$ & $\begin{array}{c}\text { 19. SECURITY CLASSIFICATION } \\
\text { OF ABSTRACT } \\
\text { Unclassified }\end{array}$ \\
\hline
\end{tabular}

